\title{
THE EXAMINATION OF APPLICATIONS OF INDUSTRY 4.0 IN ENTERPRISES BY CONTENT ANALYSIS METHOD
}

DOI: 10.17261/Pressacademia.2018.891

PAP- V.7-2018(44)-p.251-255

\section{Zeliha Tekin}

Mus Alparslan University, Mus, Turkey.

z.tekin@alparslan.edu.tr, ORCID: 000-0002-6283-0910

To cite this document

Tekin, Z. (2018). The examination of applications of industry 4.0 in enterprises by content analysis method. PressAcademia Procedia (PAP), V.7, p.251-255

Permemant link to this document: http://doi.org/10.17261/Pressacademia.2018.891

Copyright: Published by PressAcademia and limited licenced re-use rights only.

\section{ABSTRACT}

Purpose- The purpose of this study is to reveal the technological usages on which Industry 4.0 application of enterprises are based on and to show which advantages they provide.

Methodology- For this purpose, the news that were placed in national and international press in 2017 have been searched, 155 news containing the expressions of "Industry 4.0 applications" of enterprises have been framed, and content analysis has been made by investigating the web sites of 9 enterprises (Festo, Bosh, BMW, Caterpillar, KUKA, Arburg, Intel, Atos, Siemens,) using Industry 4.0 application.

Findings- It is observed that Industry 4.0 applications of enterprises included usage of technologies such as teaching/learning robots, 3 Dimensional printers, Cloud Informatics System, horizontal and vertical integration, Internet of loT Objects, virtual reality, and simulation which changed the world.

Conclusion- As a result of the research it was seen that Industry 4.0 applications of enterprises reduced costs, improved brand value, caused for increases in production, employment, performance, and efficiency, enabled increase in investments, provided opportunity to give quick response to market by means of rapid production, increased competitive power through fast prototype production and different quality productions, and enabled effective supply chain management.

Keywords: Industry 4.0, technology, production, productivity, content analysis.

JEL Codes: L23, L11, M11

\section{IŞLETMELERIN ENDÜSTRI 4.0 UYGULAMALARININ IÇERIK ANALIZI YÖNTEMIYLE INCELENMESi}

\section{ÖZET}

Amaç - Bu çalışmanın amacı, işletmelerin Endüstri 4.0 uygulamalarının hangi teknoloji kullanımlarına dayandığının ve işletmelere hangi avantajları sağladığının ortaya çıkarılmasıdır.

Yöntem - Bu amaçla 2017 yılındaki ulusal ve uluslararası basında yer alan haberler taranmış "işletmelerin Endüstri 4.0 uygulamaları" "Industry 4.0 applications" ifadelerini içeren 155 haber çerçevelenmiş, haber içeriklerinde en çok tekrar eden ve Endüstri 4.0 uygulayan 9 işletmenin (Festo, Bosh, BMW, Caterpillar, KUKA, Arburg, Intel, Atos, Siemens,) web siteleri incelenerek içerik analizi yapılmıştır.

Bulgular- Iş̧letmelerin Endüstri 4.0 uygulamalarının dünyayı değiştiren öğrenen/otonom robotlar, 3 Boyutlu $3 \mathrm{D}$ yazıcılar, Bulut Bilişim Sistemi, yatay ve dikey entegrasyon, IoT Nesnelerin İnterneti, sanal gerçeklik, simülasyon gibi teknoloji kullanımlarını içerdiği görülmüştür. Sonuç- Araştırma sonucunda, işletmelerin Endüstri 4.0 uygulamalarının maliyeti düşürdüğü, marka değeri yarattığı, üretim, istihdam, performans ve verimlilik artışına yol açtığı, yatııım artışı sağladığı, hızı üretimle pazara hızlı yanıt verebilme olanağı sunduğu, hızı prototipleme, farklı-kaliteli üretim ile rekabet gücünü arttırdığı, etkin tedarik zinciri yönetimi sağladığı görülmüştür.

Anahtar Kelimeler: Endüstri 4.0, teknoloji, üretim, verimlilik, içerik analizi.

JEL Kodları: L23, L11, M11

\section{GíRiş}

Teknolojinin günden güne gelişmesi insan emeğinin yerini makinaların almasına, buhar gücüyle çalışan makinalardan robotlu otomasyona geçilmesine ve nihayetinde günümüz dijital teknolojileri, akıllı fabrikaları, yapay zekaları içeren Endüstri 4.0 'a gelinmesine yol açmıştır. Bu 
yeni sanayi dönemi, tüketicilerin sürekli değişen ve farklı taleplerle sonuçlanan ihtiyaçlarına anlık olarak karşılık veren, üretim için lazım olan verileri bulut sisteminde depolayan, nesnelerin birbirleriyle ve insanlarla iletişime geçmesini sağlayan üretim sistemlerini temel almaktadır.

Bu çalışmada öncelikle, Endüstri 1.0'dan Endüstri 4.0'a kadar geçen süre tarihsel art alan başlığı altında anlatılmış, ardından Endüstri 4.0'ın getirmiş olduğu yeni teknolojilere değinilmiştir. Son olarak da ulusal ve uluslararası haberlerde isimleri ençok tekrar eden Endüstri 4.0 uygulayan işletmeler, internet taraması yöntemiyle tespit edilmiş, web siteleri de incelenerek içerik analizi yapılmıştır. İşletmelerdeki Endüstri 4.0 uygulamalarının işletmelere sağlamış olduğu avantajların tespiti, Endüstri 4.0 uygulamalarından en çok hangilerinin bu işletmelerce kullanıldığı çalışmanın amacını ve kapsamını oluşturmaktadır. Ayrıca yapılan bu çalışmanın Türkiye'nin Endüstri 4.0 dönüşümünün hangi noktasında olduğunu da ortaya koyması açısından önemli olduğu düşünülmektedir.

\section{TEORIK ÇERÇEVE}

\section{1. Tarihsel Art Alan: Endüstri 1. 0'dan 4. 0’a}

Alman Hükümetinin alışılagelmiş sanayisini bilgisayarlaştırma/robotlaştırma/akılı fabrikalar yönünde teşvik etme ve ileri yüksek teknolojiyle donatma projesi olan Endüstri 4.0 terimi ilk olarak 2011'de Hannover Fuarı'nda kullanılmış; Robert Bosch GmbH ve Kagermann'ın çalışma grubunun "4. Sanayi Devrimi” öneri dosyasını Alman Fedaral Hükümeti'ne sunmasıyla ve de Nisan 2013'de Alman Ulusal Bilim ve Mühendislik Akademisi'nin (Acatech) konuyu manifesto olarak yayımlamasıyla kuramsal çerçeveye kavuşmuştur (Sung, 2017: 1; Mosconi, 2015).

Endüstri 4.0, akıllı sistemler ve internet tabanlı çözümlerle karakterilize edilen, endüstrileşme devrimlerinin dördüncü nesli olarak tanımlanmaktadır. İlk endüstri devrimi, 1760-1830'lu yıllarda üretim mekanize edildiğinde gerçekleşmiştir. Makinalaşma Çağı olarak anılan 18. yüzyılda başlayıp 19. Yüzyılın ortalarına kadar süren bu endüstrileşme sürecinde, üretim evlerden ve küçük atölyelerden fabrikalara taşınmış işçi sınıfı statüsünde yeni bir sosyal sınıf doğmuştur. İkinci devrim, elektrik gücünün yardımıyla seri üretimin başladığı $1870-1913$ arasındaki dönemde gerçekleşmiş Ford'un seri üretim bandı sistemiyle ilk üretim hattını kullanması endüstrileşmeyi hızla geliştirmiştir (Kans vd., 2016: 318). Üçüncü devrim 1968'den itibaren yaşanmaya başlanmıştır. İlk Programlanabilir Mantıksal Denetleyici (Programmable Logic Controller PLC) üretiminde otomasyonu ileri aşamalara taşımak amacıyla kullanılmış ve bu dönem ile birlikte üretimde fordizm yerini postfordizme bırakmıştır (Alçın, 2016: 21).

\section{2. Endüstri 4.0'ın Getirdiği Yeni Teknolojiler}

Acatech'in Endüstri 4.0 final raporunda Endüstri 4.0'ın bünyesinde barındırdığı özellikler, bireysel müşteri isteklerine karşılık verebilme, esneklik, en uygun/optimal kararları alabilme, kaynakların verimli ve etkin bir şekilde kullanılabilmesi, yeni yöntemlerle değer yaratan yeni hizmetlerin sunulabilmesi, çalışanlar için işyerlerinde bireysel farklılıklara duyarlı iş yapısının oluşturulabilmesi (iş- yaşam dengesi), yatay dikey entegrasyon, akıllı fabrikalarda üretim, nesnelerin internetiyle (internet of things), nesnelerin birbirleriyle iletişim halinde olabilmesi şeklinde sıralanmıştır (FU\&Acatech, 2013: 15-19).

\section{Şekil 1: Endüstri 1. 0’dan 4. 0’a}

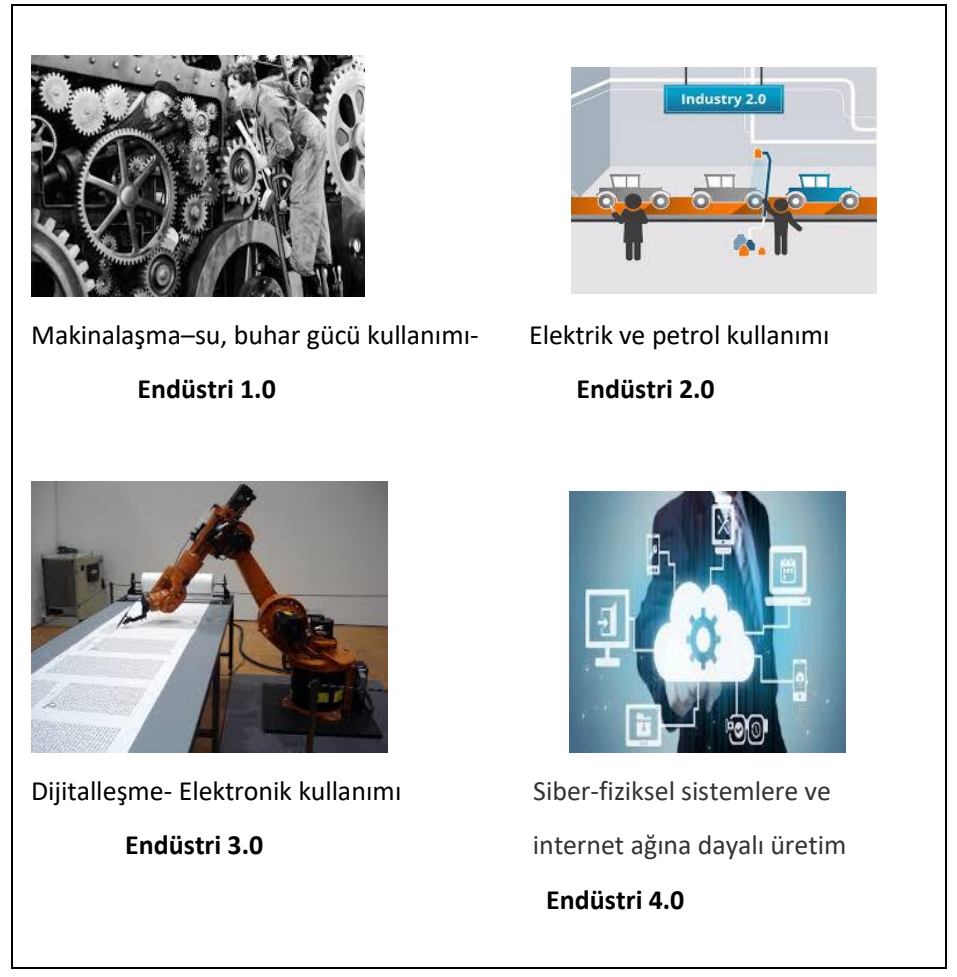


Geçmişten günümüze dört aşamadan geçmiş olan Endüstri Devriminin son aşaması, 3. Endüstri Devriminin güncellenmiş versiyonudur. Siber-fiziksel sistemleri, Nesnelerin İnternet'ini ve bulut bilgi sistemlerini içeren bu aşamada, Endüstri 3.0'da elektronikleşen üretim, bilgisayarlı üretime dönüşmüştür (Aybek, 2017: 167). 3D baskılar, çevrimiçi satış servislerinin geliştirilmesi, evde tıbbi muayenenin yapılması, mağazadan doğrudan buzdolabındaki eksik yiyeceklerin tespit edilip sipariş verilebilmesi gibi teknolojilerin kullanılması, küçük ve orta ölçekli işletmelerin değişime ayak uydurabilmelerinde önemli bir etkiye sahip olacaktır (Roblek vd., 2016: 1).

Endüstri 4.0 konusunda yerli ve yabancı araştırmacılar tarafından pek çok çalışma yapılmıştır. Sung (2017: 5) Kore'nin Dördüncü Endüstri Devrim için küresel rekabette hangi sırada olduğunu ve Koredeki işletmelerin Endüsrti 4.0'a geçişte neler yapmaları gerektiğini araştırmıştır. Roblek ve arkadaşları (2016: 1) ise Endüstri 4.0'ın bilinen teori ve uygulamalarını sentezlemeye çalışmışlar, bu yeni devrimin ne gibi değişikliklere yol açacağını belirtmişler ve nesnelerin interneti konusunu detaylıca araştırmışlardır. Lasi ve arkadaşları (2014: 239) çalışmalarında Endüstri 4.0'ın gelecekteki projelerdeki sosyal, politik ve ekonomik etkilerini tartışmışlardır. Bulut ve Akçacı (2017: 50) çalışmalarında Ar\&Ge ve iletişim göstergeleri kapsamında Türkiye ekonomisini Endüstri 4.0 açısından incelemişlerdir. Alçın (2016: 19) çalışmasında, dünyada 2011 yılından itibaren kavramsallaştırılan Sanayi 4.0'ün temel özellikleri ve olası yansımalarını tartışmışır.

\section{VERI VE YÖNTEM}

2017 yılının ulusal ve uluslararası basınında yer alan haberleri taranmış "işletmelerin Endüstri 4.0 uygulamaları" "Industry 4.0 applications" ifadelerini içeren 155 haber çerçevelenmiş, haber içeriklerinde en çok tekrar eden ve Endüstri 4.0 uygulayan 9 işletmenin (KUKA, Arburg, Intel, Festo, Bosh, Caterpillar, BMW, Siemens, Atos) web siteleri incelenerek içerik analizi yapılmıştır. Dolayısıyla bu 9 işletme, araştırmanın örneklemini oluşturmaktadır. Tabloda, internet taraması sonucunda işletmelerde teknoloji kullanımı ve işletme avantajı kriterlerinden var olanlar "var" şeklinde belirtilmiş; gerek o işletmenin web sayfasında gerekse de o işletmeyle ilgili haberlerde belirtilen bu özelliklere rastlanmamışsa o alan boş bırakılmıştır ve o alanın boş bırakııması bu özelliklerin var olmadığı anlamına gelmemektedir.

\section{BULGULAR VE TARTIŞMA}

Yapılan araştırmalar ve bu çalışmanın sonucunda Endüstri 4.0 teknoloji özellikleri ve Endüstri 4.0'ın işletmeye dolayısıyla da ekonomiye sağlayabileceği faydalar aşağıdaki şekilde gösterildiği gibi özetlenebilir.

\section{Şekil 2: Endüstri 4.0 Teknolojileri ve İşletmeye/Ekonomiye Kazandırdıkları}

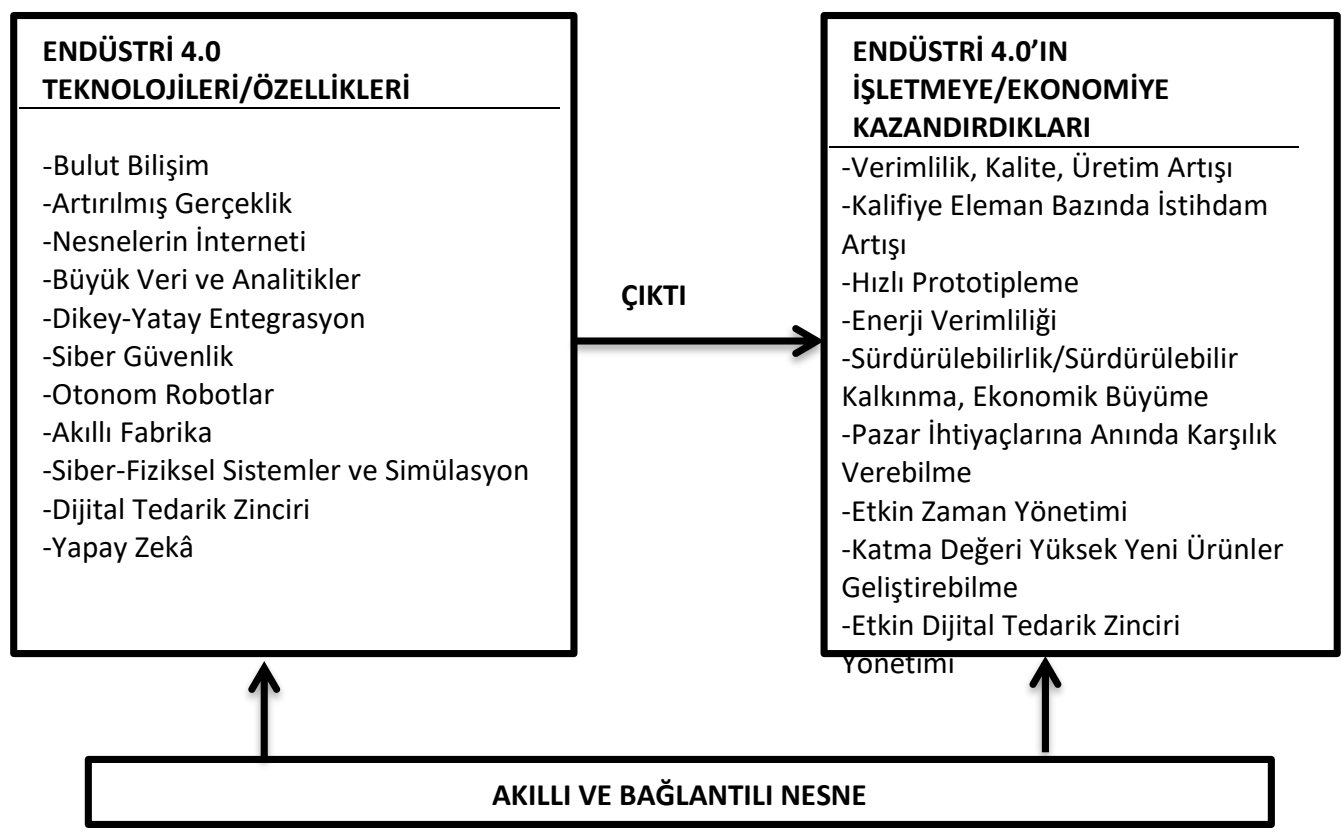

1914'te 1. Dünya Savaşı başladığında Rusya, İtalya, Kanada ve Japonya I. Endüstri Devrimi'ne henüz yeni başlamış; Türkiye, Çin, Hindistan, İspanya ise Endüstri Devrimi'ne çok geç başlayabilmiştir. Dördüncü Endüstri devrinin yaşandığı günümüzde Türkiye'nin yüksek gelirli ekonomiler arasına girebilmesi için yüksek teknolojili üretime hızla geçiş yapması gerekmektedir. Türkiye'nin sanayi üretimindeki ve ihracattaki teknoloji kullanma yoğunluğu da yüksek katma değerli ürünlere yönelmesinin gerekliliğini göstermektedir. Teknoloji seviyesi arttıkça gelir, ücretler, refah artmakta; bu da tasarruf artışıla sonuçlanmaktadır. Üretim üssü olma konusunda yarışan Türkiye için Endüstri 4.0 bir tercih değil zorunluluk olmalıdır (EBSO, 2015: 51). 
Tablo 1: Endüstri 4.0 Uygulayan İşletmeler ve Endüstri 4.0 Teknoloji Uygulamaları

\begin{tabular}{|c|c|c|c|c|c|c|c|c|c|}
\hline$\frac{\text { KRITERLER }}{\text { 1) Teknoloji kullanımı }}$ & 1 & 2 & 3 & 4 & 5 & 6 & 7 & 8 & 9 \\
\hline Nesnelerin interneti & Var & Var & Var & Var & Var & Var & Var & Var & Var \\
\hline Bulut bilişim sistemi & Var & & Var & & Var & & Var & Var & \\
\hline Akıllı fabrikalar & Var & Var & Var & Var & Var & & Var & Var & \\
\hline Artırılmış gerçeklik & Var & & & Var & Var & Var & Var & Var & Var \\
\hline Yapay zeka & Var & & & & Var & & & Var & \\
\hline $\begin{array}{l}\text { Sistem entegrasyonu } \\
\text { Dikey-yatay entegrasyon }\end{array}$ & Var & & & & Var & & & Var & Var \\
\hline $\begin{array}{l}\text { Siber-fiziksel sistemler } \\
\text { Siber güvenlik }\end{array}$ & Var & & & & Var & & & Var & Var \\
\hline Simülasyon & & Var & & Var & Var & Var & Var & Var & \\
\hline $\begin{array}{l}\text { Digital Enterprise Software Suite } \\
\text { (Dijital Girişim Yazılım Paketi) }\end{array}$ & Var & Var & & Var & Var & Var & & Var & \\
\hline $\begin{array}{l}\text { Sensörler ve Proses } \\
\text { Enstrümantasyonu }\end{array}$ & Var & Var & & Var & Var & & Var & Var & \\
\hline Radyo Frekansı ile Tanımlama & Var & & & & Var & & & Var & \\
\hline Büyük veri ve veri analitiği & Var & & Var & & Var & Var & Var & Var & Var \\
\hline $\begin{array}{l}\text { Katkı üretim } \\
\text { 3D yazıcı kullanımı }\end{array}$ & Var & Var & Var & Var & Var & Var & Var & Var & \\
\hline Akıllı/işbirlikçi robot kullanımı & Var & & & & Var & & Var & Var & \\
\hline$\frac{\text { KRITERLER }}{2)}$ işletme avantajı & & & & & & & & & \\
\hline Maliyeti düşürme & Var & Var & & Var & Var & & & Var & \\
\hline $\begin{array}{l}\text { Katma değeri yüksek } \\
\text { İnsan odaklı bir yapı }\end{array}$ & Var & & & Var & Var & & Var & Var & \\
\hline Sürdürülebilir Üretim & Var & Var & & Var & Var & & Var & Var & \\
\hline Performans artışı & Var & & & Var & Var & & Var & Var & \\
\hline Verimlilik artışı (Enerji vb.) & Var & Var & Var & Var & Var & Var & Var & Var & \\
\hline Yatırım artışı & Var & & & Var & Var & & & Var & \\
\hline $\begin{array}{l}\text { Hızlı /Esnek Üretim/ } \\
\text { Pazara hızlı yanıt verebilme }\end{array}$ & Var & Var & & Var & Var & & Var & Var & \\
\hline Hızlı prototipleme & Var & Var & & Var & Var & & Var & Var & \\
\hline Farklı ve kaliteli üretim & Var & Var & & Var & Var & & Var & Var & \\
\hline Etkin tedarik zinciri yönetimi & Var & Var & & Var & Var & & Var & Var & \\
\hline
\end{tabular}

${ }^{1}$ KUKA, ${ }^{2}$ ARBURG, ${ }^{3}$ INTEL, ${ }^{4}$ FESTO, ${ }^{5}$ BOSH, ${ }^{6}$ CATERPILLAR, ${ }^{7} B M W,{ }^{8}$ SIEMENS, ${ }^{9}$ ATOS

\section{SONUÇ}

Dijital dönüşümün en büyük dalgası olan Endüstri 4.0 içerdiği loT Nesnelerin Interneti, 3 Boyutlu 3D Yazıcılar, Büyük Veri, Otonom Robotlar, Simülasyon, Sistem Entegrasyonu, Bulut Bilişim Sistemi gibi uygulamalarla işletmelere enerji ve kaynak verimliliği sağlayabilecek, akıllı üretim sistemleri kullanımı sayesinde değer zincirinin parçası olan insan, makine, araç, malzeme gibi unsurlar arasında entegrasyon sağlanarak çalş̧anlar rutin ve önemsiz sayılan işlerden kurtulacaktır. 4.0 uygulamalarıyla kişisel farklılıklara duyarlı iş yapısı oluşturulabilecektir. İşletmelerdeki üretim birimleri, akıllı fabrikalardaki yapay zekâ uygulamalarıla yeni üretim süreçlerine eklemlenebilecek ve hammadde, mamullerin üretim makineleriyle iletişimi sağlanarak kişiselleştirilmiş, katma değeri yüksek farklı ürünler kolaylıkla üretilebilecektir. Üretim tek makinalı sistemden çok makinalı sisteme dönüșeceği için üretim hızı, kalitesi ve verimliliği artacaktır. Zamanın etkin kullanımıyla üretim süresi azalabilecek, daha az enerji ve maliyetle daha fazla üretim yapılabilecek, siparişler zamanında yetişebilecek, yönetimde verimlilik artacaktır.

\section{KAYNAKLAR}

Alçın, S. (2016). Üretim için yeni bir izlek: sanayi 4.0. Journal of Life Economics, sayı 8, s.19-30.

Arburg. (2016). Industry 4.0: networked production in the digital factory offers a competitive edge.

Aybek, H. S. Y. (2017). Üniversite 4.0'a geçiş süreci: kavramsal bir yaklaşım. AUAd, 3(2), 164-176

BOSCH (2017). Industry 4.0 at Bosch Product Catalog

EBSO (2015). Sanayi 4.0. Ege Bölgesi Sanayi Odası Yayınları. 
FU., Acatech (2013). Securing the future of Germany manufacturing industry - recommendations for implementing the strategic initiative INDUSTRIE 4.0 - Final report.

Huber, A. S. (2014). Siemens - contribution from the technical book "Industry 4.0" Title: The goal is the digital enterprise: Professional digital representation of product development and production, Springer Vieweg.

Kans, M., Diego Galar, D., Thaduri, A. (2016). Proceedings of the 10th World Congress on Engineering Asset Management, Lecture Notes in Mechanical Engineering, Title: Maintenance 4.0 in Railway Transportation Industry, Eds: Kari T. Koskinen, K. T., Kortelainen, H., Jussi Aaltonen, J., Springer, p.317-332.

KUKA (2017). Hello Industrie 4.0- we connect you.

Lasi, H., Fettke, P., Kemper, H. G., Feld, T., Hoffmann, M. (2014). Industry 4.0, business \& information systems engineering, 6(4), pp. 239242.

McKinsey \& Company. (2015). Industry 4.0 how to navigate digitization of the manufacturing sector. McKinsey Digital.

Mosconi, F. (2015). The new European industrial policy: global competitiveness and the manufacturing renaissance. London, England: Routledge.

Roblek, V., Meško. M., Krapež, A. (2016). A complexity view of Industry 4.0. SAGE, 6(2), p. 1-11

Sung, T. K. (2017). Industry 4.0: A Korea perspective. Technological Forecasting \& Social Change, p.1-6.

https://www.intel.com.tr/.../powering-industry-smart-manufacturing-transformations-brie..., ediniliş tarihi: 13.02.2018.

https://www.bmwgroup.com/en/.../industrie-4-0.html, ediniliş tarihi: 13.02.2018.

https://www.press.bmwgroup.com/.../industry-4-0:-intellige... , ediniliş tarihi: 13.02.2018.

www.greencarcongress.com/2015/08/20150811-bmw.html, ediniliş tarihi: 13.02.2018.

gts-net.dk/wp-content/uploads/2015/11/BMW.pdf, ediniliş tarihi: 13.02.2018.

https://www.mckinsey.de/files/mck_industry_40_report.pdf, ediniliş tarihi: 13.02.2018.

https://www.automationworld.com/.../industry.../caterpillars-.. ediniliş tarihi: 13.02.2018.

siemens.e-dergi.com/pubs/Endustri40/Endustri40/assets/common/.../page0001.pdf, ediniliş tarihi: 16.02.2018. 